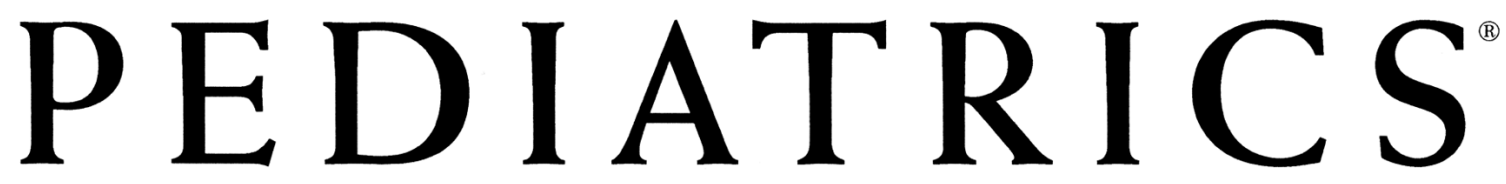

OFFICIAL JOURNAL OF THE AMERICAN ACADEMY OF PEDIATRICS

\title{
XXY (Klinefelter Syndrome): A Pediatric Quantitative Brain Magnetic Resonance Imaging Case-Control Study
}

Jay N. Giedd, Liv S. Clasen, Gregory L. Wallace, Rhoshel K. Lenroot, Jason P. Lerch,

Elizabeth Molloy Wells, Jonathan D. Blumenthal, Jean E. Nelson, Julia W. Tossell, Catherine Stayer, Alan C. Evans and Carole A. Samango-Sprouse

Pediatrics 2007;119; $232-\mathrm{e} 240$

DOI: $10.1542 /$ peds.2005-2969

The online version of this article, along with updated information and services, is located on the World Wide Web at:

http://www.pediatrics.org/cgi/content/full/119/1/e232

PEDIATRICS is the official journal of the American Academy of Pediatrics. A monthly publication, it has been published continuously since 1948. PEDIATRICS is owned, published, and trademarked by the American Academy of Pediatrics, 141 Northwest Point Boulevard, Elk Grove Village, Illinois, 60007. Copyright ( 2007 by the American Academy of Pediatrics. All rights reserved. Print ISSN: 0031-4005. Online ISSN: 1098-4275.

\section{American Academy of Pediatrics}




\section{XXY (Klinefelter Syndrome): A Pediatric Quantitative Brain Magnetic Resonance Imaging Case-Control Study}

Jay N. Giedd, MDa, Liv S. Clasen, PhDa , Gregory L. Wallace, MAa , Rhoshel K. Lenroot, MD ${ }^{a}$, Jason P. Lerch, PhD ${ }^{b}$, Elizabeth Molloy Wells, MDa, Jonathan D. Blumenthal, MA ${ }^{a}$, Jean E. Nelson, MHSa, Julia W. Tossell, MDa , Catherine Stayer, MD, PhDa , Alan C. Evans, PhD ${ }^{b}$, Carole A. Samango-Sprouse, EdDc,d

aChild Psychiatry Branch, National Institute of Mental Health, National Institutes of Health, Bethesda, Maryland; bMcConnell Brain Imaging Centre, Montreal Neurological Institute, McGill University, Montreal, Quebec, Canada; 'Department of Pediatrics, George Washington University, Washington, DC; dNeurodevelopmental Diagnostic Center for Young Children, Davidson, Maryland

The authors have indicated they have no financial relationships relevant to this article to disclose.

\section{ABSTRACT}

OBJECTIVE. An extra X chromosome in males (XXY), known as Klinefelter syndrome, is associated with characteristic physical, cognitive, and behavioral features of variable severity. The objective of this study was to examine possible neuroanatomical substrates of these cognitive and behavioral features during childhood and adolescence.

METHODS. MRI brain scans were acquired for $42 \mathrm{XXY}$ and 87 healthy XY agematched control males. We compared these 2 groups on regional brain volumes and cortical thickness.

RESULTS. Total cerebral volume and all lobar volumes except parietal white matter were significantly smaller in the XXY group, whereas lateral-ventricle volume was larger. Consistent with the cognitive profile, the cortex was significantly thinner in the XXY group in left inferior frontal, temporal, and superior motor regions.

CONCLUSION. The brain-imaging findings of preferentially affected frontal, temporal, and motor regions and relative sparing of parietal regions are consistent with observed cognitive and behavioral strengths and weaknesses in XXY subjects. www.pediatrics.org/cgi/doi/10.1542/ peds.2005-2969

doi:10.1542/peds.2005-2969

Key Words

sex chromosome aneuploidy, Klinefelter syndrome, magnetic resonance imaging, children, adolescents, brain, XXY

\section{Abbreviations}

KS — Klinefelter syndrome

TCV—-total cerebral volume

TRT-testosterone-replacement therapy

$\mathrm{NIH}$-National Institutes of Health

CSF-cerebrospinal fluid

ANOVA - analysis of variance

ANCOVA—analysis of covariance

SES-socioeconomic status

Accepted for publication Jul 26, 2006

Address correspondence to Jay N. Giedd, MD, Child Psychiatry Branch/NIMH, Building 10, Room 4C110, 10 Center Dr, MSC 1367, Bethesda, MD 20892. E-mail: jg@nih.gov PEDIATRICS (ISSN Numbers: Print, 0031-4005; Online, 1098-4275). Copyright $\odot 2007$ by the American Academy of Pediatrics 
K LINEFELTER SYNDROME (KS) (also known as $47, \mathrm{XXY})$, the occurrence of an additional X chromosome in males, is the most common sex-chromosome aneuploidy and is found in between 1 of $600^{1,2}$ and 1 of $1000^{3}$ live male births. Supernumerary X chromosomes typically arise from nondisjunction during either maternal or paternal meiotic cell division ${ }^{4}$ and can affect development of the cardiac, endocrine, reproductive, skeletal, and central nervous systems.

The original phenotype, described by Hans Klinefelter in 1942,5 consisted of hypogonadism, gynecomastia, sparse body hair, eunuchoid body habitus, above-average height, and infertility. Other physical characteristics subsequently identified included long legs and arm span, decreased bone mineral density, taurodontism, ${ }^{6}$ and low testosterone levels. Except for hypogonadism, which is present in nearly all individuals with XXY, the physical phenotype may be quite variable. Because there is some debate regarding whether those with XXY without the KS phenotype should be assigned the KS diagnosis, for this report we will use the designation XXY.

Similar to those with the physical phenotype, XXY males have characteristic but highly variable cognitive and behavioral features. The most frequently documented cognitive impairments, occurring in $\sim 80 \%$ of those with XXY, are language-based learning disorders. ${ }^{7-12}$ Graham et al ${ }^{13}$ found that $\sim 50 \%$ of boys with XXY were reading 1 or more grade levels below average for their age. Also common are disorders of executive function, ${ }^{14,15}$ particularly difficulties with planning ${ }^{12}$ and inhibitory control. ${ }^{16}$ Motor delay with truncal hypotonia and motor planning deficits have been observed in infancy and throughout childhood.17,18 Other deficits reported in XXY have been in short-term auditory memory ${ }^{13,17}$ and auditory processing. ${ }^{19,20}$ In contrast, visualspatial processing (eg, facility with puzzles, computers, and machinery) seems to be relatively preserved, and in some cases enhanced, in XXY males. ${ }^{19,21,22}$

Few studies have been conducted regarding possible neurobiological substrates of the observed cognitive and behavioral phenotypes. Decreased head circumference has been found in children with KS from birth to 9 years of age. ${ }^{23}$ MRI findings in adults have implicated reduced left temporal lobe gray matter, ${ }^{2}$ smaller total cerebral volume (TCV), a decrease in amygdala volume in the presence of preserved hippocampal volume, ${ }^{24}$ and bilaterally enlarged lateral ventricles. ${ }^{25}$

In this study we used MRI to investigate the effects of a supernumerary $\mathrm{X}$ chromosome in a relatively large sample of children and adolescents with XXY. Pediatric subjects were studied earlier in their developmental trajectories than adults and have had less time in which to be exposed to environmental influences. Therefore, they may be better suited than an adult population for elucidating early neurobiological effects of the additional $\mathrm{X}$ chromosome.

On the basis of these previously identified cognitive features, we hypothesized that we would find:

1. smaller TCV in subjects with XXY compared with control subjects, consistent with smaller head size;

2. decreased cortical thickness, specifically in the left temporal, prefrontal, and motor cortices, which are brain regions thought to underlie cognitive impairments commonly observed in subjects with XXY; and

3. preserved parietal cortex in the XXY group commensurate with their relatively good visual-spatial skills.

\section{METHODS}

\section{Participants}

The XXY group consisted of 42 nonmosaic XXY males ranging in age from 5.3 to 26.0 years (Table 1). The ethnic composition of the XXY group was 40 white, 1 black, and 1 Hispanic. Thirty-three subjects were righthanded, 4 were left-handed, and 5 were mixed-handed. One of the XXY boys was born premature at 35 weeks' gestation, and the remaining 41 had gestational ages of $\geq 37$ weeks.

Consistent with current clinical practice guidelines, none of the $24 \mathrm{XXY}$ males aged $\leq 12$ were undergoing testosterone-replacement therapy (TRT), and all 14 of

TABLE $1 \quad X X Y$ and XY Demographics

\begin{tabular}{|c|c|c|c|c|c|c|}
\hline & \multicolumn{2}{|c|}{$X X Y(N=42)$} & \multicolumn{2}{|c|}{$\mathrm{XY}(N=87)$} & \multirow[t]{2}{*}{$t$} & \multirow[t]{2}{*}{$P$} \\
\hline & Mean (SD) & $n$ & Mean (SD) & $n$ & & \\
\hline Age, $y$ & $12.8(5.0)$ & 42 & $12.7(5.0)$ & 87 & 0.1 & .902 \\
\hline Height, in & $61.6(9.9)$ & 42 & $60.1(9.1)$ & 84 & 0.9 & .386 \\
\hline Height age $<13$ y & $54.4(6.3)$ & 24 & $54.0(6.0)$ & 49 & 0.3 & .787 \\
\hline Height age $\geq 13 y$ & $71.2(3.6)$ & 18 & $68.6(4.7)$ & 35 & 2.1 & $.041^{a}$ \\
\hline Weight, lb & $118.2(62.8)$ & 42 & $110.5(47.4)$ & 86 & 0.7 & .485 \\
\hline Tanner stage & $2.8(1.5)$ & 41 & $2.8(1.6)$ & 86 & 0.0 & .979 \\
\hline SES & $51.0(22.7)$ & 42 & $38.6(20.7)$ & 83 & 3.1 & $.003^{a}$ \\
\hline IQ & $95.2(17.1)$ & 39 & $120.3(11.3)$ & 82 & 8.4 & $<.0001^{\mathrm{a}}$ \\
\hline Vocabulary & $8.1(3.4)$ & 39 & $13.2(2.5)$ & 82 & 8.3 & $<.0001^{\mathrm{a}}$ \\
\hline Block design & $10.0(3.4)$ & 39 & $13.6(2.7)$ & 82 & 6.2 & $<.0001^{\mathrm{a}}$ \\
\hline
\end{tabular}


the XXY males aged $\geq 14$ were undergoing TRT. Of the 4 remaining XXY boys (all aged 13 years), 2 were undergoing TRT and 2 were not. Because the ages of the TRT and non-TRT XXY subgroups were so disparate, it was not possible to examine the effects of TRT on brain morphometry in our sample.

We recruited XXY males nationwide with the help of 2 parent advocacy groups: the American Association for Klinefelter Syndrome Information and Support (AAKSIS) and Klinefelter Syndrome and Associates (KS\&A). Parents of XXY males were interviewed by telephone and asked to report their child's health, developmental, and educational history. Children with severe head injuries or other conditions that might have affected gross brain development were not accepted into the study.

During their visit to the National Institutes of Health (NIH), subjects underwent physical and neurologic assessment and IQ testing (using the Wechsler Scales of Intelligence ${ }^{26-28}$ ) whenever possible (IQ was not obtained for 3 XXY participants: 1 because of refusal to undergo testing and 2 because of scheduling difficulties). The presence of XXY was confirmed with karyotype testing on all subjects. High resolution G-band karyotyping was performed on phytohemagglutinin-stimulated patient peripheral blood cultures. A minimum of 50 metaphases were analyzed, and 3 karyotypes per patient were produced. (All karyotyping was performed by the Cytogenetics Laboratory, Department of Obstetrics and Gynecology, Georgetown University Hospital.) Subjects were included on the basis of an XXY karyotype and not on the presence of the characteristic Klinefelter phenotype or other specific clinical features. However, we did note that, generally consistent with the extant literature, ${ }^{7-9,11}$ $30(71 \%)$ of the $42 \mathrm{XXY}$ males in our sample had been diagnosed with speech and/or language delays.

Eighty-seven healthy XY males ranging in age from 5.2 to 25.5 years were selected as controls. These controls were age-matched to the $42 \mathrm{XXY}$ boys in the sample. They were a subset of healthy volunteers recruited from the community through the NIH Normal Volunteer Office, newspaper advertisements, and outreach to Washington, DC, area schools. The ethnic composition of this group was 80 white, 2 black, 1 Asian, 1 Hispanic, and 3 biracial (black/white). Eighty controls were righthanded, 4 were left-handed, and 3 were mixed-handed. One of the XY boys was born premature at 34 weeks' gestation, and the remaining 86 were born term at gestational ages of $\geq 37$ weeks.

Healthy controls were screened via an initial telephone interview, parent and teacher rating versions of the Child Behavior Checklist, ${ }^{29}$ and physical and neurologic assessment. Exclusion criteria included psychiatric diagnosis in the subject or a first-degree relative and head injury or other conditions that might have affected gross brain development.

IQ scores were obtained by using the Wechsler scales in the form of the full test, the 4-subtest abbreviated version (the Wechsler Abbreviated Scale of Intelligence), or the 2-subtest (vocabulary and block design) short form scored by using Sattler's technique. ${ }^{30}$ Five control participants did not receive IQ assessment, all because of scheduling difficulties. Because healthy control participants were taking part in an ongoing longitudinal study of brain development, several different versions of the Wechsler IQ tests were used depending on the time of assessment.

For all study participants, handedness was assessed by using the Physical and Neurological Examination for Soft Signs (PANESS). ${ }^{31}$ In this examination, individuals are asked to write their name and then demonstrate how they perform 11 other activities (eg, throwing a ball, using a saw, etc). If a child writes with his or her right hand and performs 10 or all of the remaining 11 items with the right hand (or right hand first, indicating preference), the child is categorized as right-handed. Conversely, if the child writes with his or her left hand and performs 10 or all of the remaining 11 items with the left hand (or left hand first), the child is categorized as left-handed. All other outcomes result in categorization as mixed-handed.

We obtained verbal or written assent from the child and written consent from the parents for their participation in the study. The National Institute of Mental Health Institutional Review Board approved the protocol.

\section{MRI Acquisition}

All images were acquired on the same General Electric 1.5-T Signa scanner (Waukesha, WI), which was located at the NIH clinical center in Bethesda, Maryland. A 3-dimensional spoiled-gradient recalled-echo sequence in the steady-state sequence, designed to optimize discrimination between gray matter, white matter, and cerebrospinal fluid (CSF), was used to acquire 124 contiguous $1.5-\mathrm{mm}$-thick slices in the axial plane (echo time: 5 milliseconds; repetition time: 24 milliseconds; flip angle: 45; matrix: $256 \times 192$; number of excitations: 1; field of view: $24 \mathrm{~cm}$; acquisition time: 9 minutes, 52 seconds). A fast-spin-echo/proton-density weighted imaging sequence was also acquired for clinical evaluation.

\section{Quantification of Cortical Thickness and Regions of Interest}

The native MRI scans were registered into standardized stereotaxic space by using a linear transformation ${ }^{32}$ and corrected for nonuniformity artifacts. ${ }^{33}$ The registered and corrected volumes were segmented into white matter, gray matter, and CSF by using a neural net classifier. ${ }^{34}$ Region-of-interest analysis was performed by combining tissue-classification information with a probabilistic atlas. The regions that had been validated by comparison with other methods were the midsagittal area of the corpus callosum; volumes of the cerebellum, 
caudate nucleus, and lateral ventricles; and gray and white matter volumes of the total cerebrum, frontal lobes, parietal lobes, and temporal lobes. ${ }^{35}$

To measure cortical thickness, white and gray matter surfaces were fitted by using deformable models, ${ }^{36}$ resulting in 2 surfaces with 81920 polygons each. This surface-deformation algorithm first fits the white matter surface and then expands outward to find the gray matter-CSF intersection, defining a known relationship between each vertex of the white matter surface and its gray matter surface counterpart; thus, cortical thickness can be defined as the distance between these linked vertices. The thickness measurements were obtained in native space and blurred with a $30-\mathrm{mm}$ surface-based diffusion-smoothing kernel. ${ }^{37}$ Multiple comparisons were controlled for by defining statistical significance using the false-discovery rate set at $q=0.05$ (ie, an average of $5 \%$ of the results shown will be false-positive). ${ }^{38}$

\section{Statistical Analysis}

Demographic and IQ differences between groups were assessed with independent-samples $t$ tests. We performed outlier analysis on all of the brain morphometric data, and extreme outliers (defined as $\geq 3$ SDs above or below the mean) were removed ( $3 \mathrm{XXY}$ high lateralventricle values and $2 \mathrm{XY}$ high lateral-ventricle values). After the removal of extreme outliers, brain morphometric data were analyzed by using analysis of variance (ANOVA), with diagnosis as the between-group factor, as well as analysis of covariance (ANCOVA) adjusted for (1) TCV, (2) TCV and socioeconomic status (SES), and (3) TCV, SES, and IQ. Two-tailed significance levels were used at $P \leq .05$. To identify differences between groups in cortical thickness at each vertex, $t$ tests were used; multiple comparisons were controlled via the previously described false-discovery rate. ${ }^{39}$

\section{RESULTS}

The age difference between the XXY and control groups was nonsignificant (Table 1). The 2 groups also were not significantly different with regards to weight. Although height was not significantly different in the sample as a whole, among those who were $\geq 13$ years old, XXY males were taller than XY males. Control families had a higher mean SES ${ }^{40}$ than the families of XXY males (a lower score indicates higher SES).

Control males had higher full-scale IQs and vocabulary and block-design subtest scores than XXY males. However, it should be noted that the XXY group's mean IQ was in the average range (90-109) and that the dramatic IQ difference between the XXY and control groups is largely attributable to the high mean IQ of the control group. Given that the exclusion criteria for controls in our study are more strict than those on which the
IQ tests were formed, the higher-than-average mean for our control group was not unexpected. In addition, the XXY group's mean block-design score was higher than their mean vocabulary subtest score, consistent with the KS cognitive phenotype of poorer verbal than spatial ability.

As shown in Table 2, lateral-ventricle volume was $27 \%$ larger, and TCV was $7 \%$ smaller in subjects with XXY. Without adjustment for TCV, all regional volumes except parietal white matter were significantly smaller in the XXY group. When adjusted for the TCV difference, frontal and temporal gray matter remained significantly smaller in the XXY group. Parietal gray matter was not significantly different after controlling for TCV, whereas parietal white matter was significantly larger in the XXY group.

The caudate nucleus was $\sim 10 \%$ smaller in the XXY group and remained significantly smaller after controlling for TCV. The cerebellum was $\sim 5 \%$ smaller in the $\mathrm{XXY}$ group but was not significantly different after controlling for TCV. The midsagittal corpus callosum area was not significantly different between groups with or without controlling for TCV. Figure 1 shows XXY and healthy control volumes of frontal, temporal, and parietal gray matter volumes and caudate nucleus volumes.

An additional ANCOVA was conducted which controlled for TCV and SES to determine if the differences in SES between the 2 groups influenced the volumetric outcomes. After controlling for TCV and SES, all of the significant results found after controlling for TCV alone remained significant in the same direction. In addition, frontal white matter volumes were significantly larger in XXY boys than in controls after controlling for TCV and SES.

Because the control group's mean IQ was more than 1 SD higher than the population average, we conducted an additional ANCOVA, adding IQ to the control variables TCV and SES. All of the significant results of the ANCOVA controlling for TCV and SES remained significant in the same direction with the exception of frontal white matter, which was no longer significant.

Figure 2 contains maps of cortical thickness at each surface vertex. The top 2 images (Fig 2 A and B) show group mean differences in cortical thickness, and the bottom 2 images (Fig 2 C and D) show the statistical significance of these differences. These results depict widespread differences in the temporal lobes bilaterally and the inferior parietal lobes (particularly left-sided), with XXY males showing thinner cortex than XY males. Also prominent is thinner cortex among XXY males in the left inferior frontal area and the motor strip, particularly on the left. In contrast, cortical-thickness differences in the superior parietal lobes bilaterally failed to reach statistical significance. 
TABLE 2 Regional XXY and XY Brain Volumes ( $\mathrm{mL}$ ), Unadjusted and Adjusted for (1) TCV, (2) TCV and SES, and (3) TCV, SES, and IQ

\begin{tabular}{|c|c|c|c|c|c|}
\hline Brain Structure & Covariates & $\begin{array}{c}\mathrm{XXY}(N=42), \text { Mean }(\mathrm{SD}) / \\
\text { EM Mean }(\mathrm{SE}), \mathrm{mL}\end{array}$ & $\begin{array}{c}\mathrm{XY}(\mathrm{N}=87), \text { Mean }(\mathrm{SD}) / \\
\mathrm{EM} \text { Mean }(\mathrm{SE}), \mathrm{mL}\end{array}$ & $\begin{array}{l}\text { ANOVA/ } \\
\text { ANCOVA, F }\end{array}$ & $P$ \\
\hline TCV & None & $1066.6(119.3)$ & $1145.8(103.4)$ & 15.0 & $<.001^{\mathrm{a}, \mathrm{b}}$ \\
\hline Gray matter & None & $681.7(69.0)$ & $742.5(71.1)$ & 21.1 & $<.0001^{a, b}$ \\
\hline \multirow[t]{4}{*}{ Frontal gray matter } & None & $205.9(20.7)$ & $227.8(23.5)$ & 26.5 & $<.0001^{\mathrm{a}, \mathrm{b}}$ \\
\hline & TCV & $215.2(2.0)$ & $223.3(1.4)$ & 10.7 & $.0014^{a, b}$ \\
\hline & TCV, SES & $214.7(2.0)$ & $223.7(1.4)$ & 12.5 & $<.001^{\mathrm{a}, \mathrm{b}}$ \\
\hline & TCV, SES, IQ & $215.4(2.4)$ & $224.9(1.5)$ & 8.9 & $.003^{\mathrm{a}}$ \\
\hline \multirow[t]{4}{*}{ Temporal gray matter } & None & $170.5(15.1)$ & $187.6(16.5)$ & 32.1 & $<.0001^{a, b}$ \\
\hline & TCV & $177.3(1.3)$ & $184.3(0.9)$ & 18.8 & $<.0001^{\mathrm{a}, \mathrm{b}}$ \\
\hline & TCV, SES & $177.0(1.3)$ & $184.7(0.9)$ & 20.9 & $<.0001^{\mathrm{a}, \mathrm{b}}$ \\
\hline & TCV, SES, IQ & $177.9(1.6)$ & $185.1(1.0)$ & 11.6 & $.001^{\mathrm{a}, \mathrm{b}}$ \\
\hline \multirow[t]{4}{*}{ Parietal gray matter } & None & $113.2(14.5)$ & $122.2(13.6)$ & 11.6 & $<.001^{\mathrm{a}, \mathrm{b}}$ \\
\hline & TCV & $118.5(1.4)$ & $119.6(1.0)$ & 0.4 & .517 \\
\hline & TCV, SES & $118.1(1.5)$ & $119.8(1.0)$ & 0.9 & .353 \\
\hline & TCV, SES, IQ & $119.5(1.7)$ & $119.9(1.1)$ & 0.0 & .862 \\
\hline White matter & None & $384.9(67.3)$ & $403.3(51.4)$ & 3.0 & .087 \\
\hline \multirow[t]{4}{*}{ Frontal white matter } & None & $142.1(25.8)$ & $150.5(18.8)$ & 4.5 & $.037^{\mathrm{a}}$ \\
\hline & TCV & $150.6(2.0)$ & $146.4(1.4)$ & 2.8 & .098 \\
\hline & TCV, SES & $151.6(2.0)$ & $146.6(1.4)$ & 4.0 & $.048^{\mathrm{a}}$ \\
\hline & TCV, SES, IQ & $149.9(2.4)$ & $147.9(1.5)$ & 0.4 & .520 \\
\hline \multirow[t]{4}{*}{ Temporal white matter } & None & $78.7(13.4)$ & $84.1(11.2)$ & 5.7 & $.018^{a}$ \\
\hline & TCV & $83.0(1.3)$ & $82.0(0.9)$ & 0.4 & .550 \\
\hline & TCV, SES & $83.4(1.3)$ & $82.3(0.9)$ & 0.4 & .529 \\
\hline & TCV, SES, IQ & $82.9(1.6)$ & $82.3(1.0)$ & 0.1 & .748 \\
\hline \multirow[t]{4}{*}{ Parietal white matter } & None & $76.3(13.0)$ & $79.6(10.8)$ & 2.4 & .126 \\
\hline & TCV & $80.9(1.1)$ & $77.4(0.7)$ & 6.7 & $.011^{\mathrm{a}}$ \\
\hline & TCV, SES & $81.3(1.1)$ & $77.5(0.7)$ & 8.0 & $.006^{a}$ \\
\hline & TCV, SES, IQ & $81.3(1.3)$ & $77.4(0.8)$ & 5.3 & $.023^{a}$ \\
\hline \multirow[t]{4}{*}{ Caudate } & None & $9.8(1.2)$ & $10.9(1.1)$ & 28.3 & $<.0001^{\mathrm{a}, \mathrm{b}}$ \\
\hline & TCV & $10.1(0.2)$ & $10.8(0.1)$ & 12.6 & $.005^{\mathrm{a}}$ \\
\hline & TCV, SES & $10.1(0.2)$ & $10.7(0.1)$ & 9.0 & $.003^{a, b}$ \\
\hline & TCV, SES, IQ & $10.1(0.2)$ & $10.8(0.1)$ & 8.3 & $.005^{\mathrm{a}}$ \\
\hline \multirow[t]{4}{*}{ Cerebellum } & None & $128.3(12.3)$ & $135.6(11.3)$ & 11.2 & $.001^{\mathrm{a}, \mathrm{b}}$ \\
\hline & TCV & $132.5(1.3)$ & $133.6(0.9)$ & 0.4 & .515 \\
\hline & TCV, SES & $133.0(1.3)$ & $133.6(0.9)$ & 0.1 & .741 \\
\hline & TCV, SES, IQ & $131.7(1.6)$ & $134.4(1.0)$ & 1.7 & .201 \\
\hline \multirow{4}{*}{ Corpus callosum area, mm² } & None & $535.9(91.8)$ & $541.9(77.4)$ & 0.3 & .558 \\
\hline & $\mathrm{TCV}$ & $550.2(12.0)$ & $533.6(8.2)$ & 1.3 & .265 \\
\hline & TCV, SES & $553.3(12.2)$ & $533.1(8.5)$ & 1.7 & .193 \\
\hline & $\mathrm{TCV}, \mathrm{SES}, \mathrm{IQ}$ & $540.8(14.7)$ & $536.8(9.4)$ & 0.0 & .838 \\
\hline \multirow[t]{4}{*}{ Lateral ventriclesc } & None & $13.6(8.3)$ & $10.7(4.7)$ & 9.3 & $.003^{a, b}$ \\
\hline & $\mathrm{TCV}$ & $14.0(0.8)$ & $10.5(0.5)$ & 12.9 & $<.001^{\mathrm{a}, \mathrm{b}}$ \\
\hline & TCV, SES & $13.8(0.8)$ & $10.8(0.6)$ & 8.8 & $.004^{\mathrm{a}, \mathrm{b}}$ \\
\hline & $\mathrm{TCV}, \mathrm{SES}, \mathrm{IQ}$ & $13.6(1.0)$ & $10.9(0.6)$ & 4.3 & $.040^{\mathrm{a}}$ \\
\hline
\end{tabular}

EM mean indicates estimated marginal mean.

a Statistically significant.

b ANOVA/ANCOVA survived Bonferroni adjustment at $P<.0048$ (.05/13 comparisons [number of structures])

c For lateral ventricles, $X X Y n=39$ and $X Y n=85$ ( $3 X X Y$ and $2 X Y$ extreme high outliers were dropped).

\section{DISCUSSION}

In this study we found both general and regionally specific effects of a supernumerary $\mathrm{X}$ chromosome on brain development. TCV was found to be smaller in XXY individuals. Specific effects include thinner cortex in temporal and frontal regions, smaller frontal, temporal, and caudate volumes, and preserved parietal regions, all consistent with the cognitive/behavioral phenotypes reported for XXY such as impaired language function.

The frontal and caudate findings seen here are similar to those seen in MRI studies of attention-deficit/hyperactivity disorder, a similarity which suggests that anom- alies of frontal-striatal circuitry ${ }^{41}$ may also underlie aspects of executive dysfunction in XXY. ${ }^{14,16,22}$ These structures, along with the preferential thinning of motor cortex, may also contribute to impairment in the planning and integration of motor movements..$^{8,18}$ The areas of the motor strip in which cortical thinning is most prominent are the superior region, associated with control of the upper trunk and shoulders, a noted area of muscular weakness in XXY, and the left inferior region, associated with control of the anatomy involved in speech production such as the lips, jaw, and pharynx. ${ }^{42}$ Dyspraxia in these areas has been hypothesized to con- 

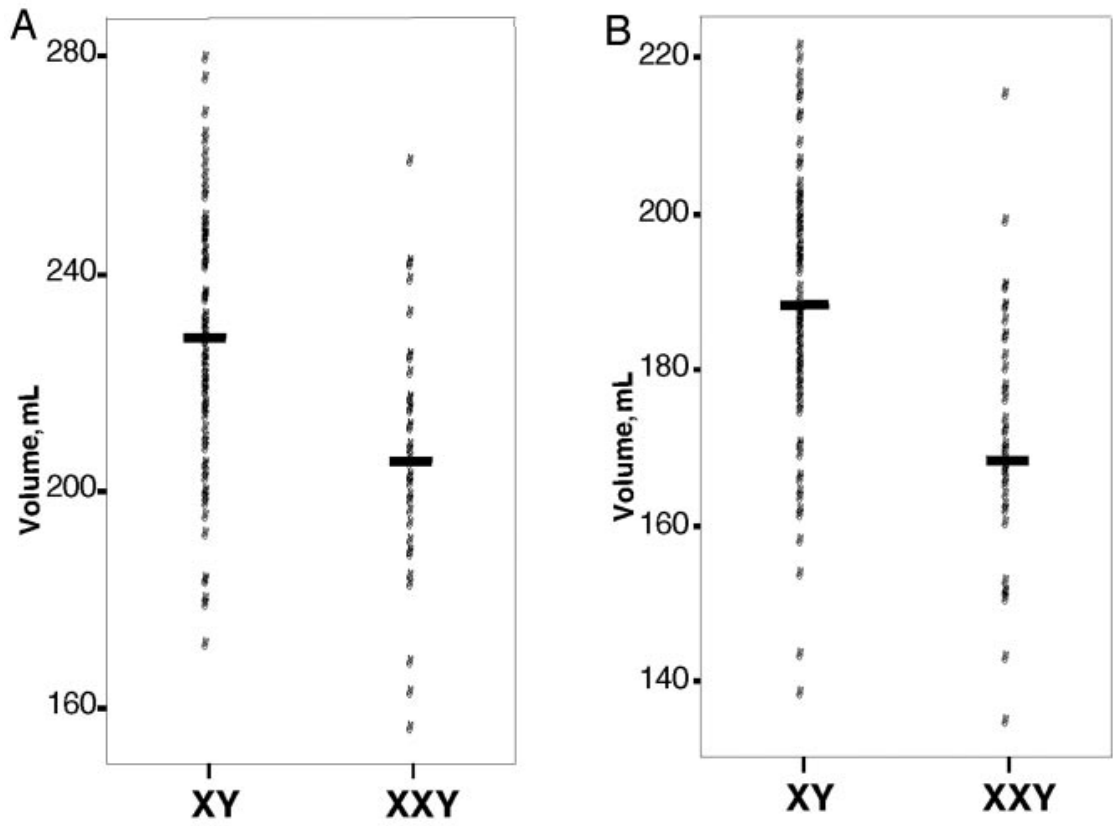

$X Y$ and $X X Y$ frontal (A), temporal (B), and parietal (C) gray matter volumes and caudate nucleus volumes (D).
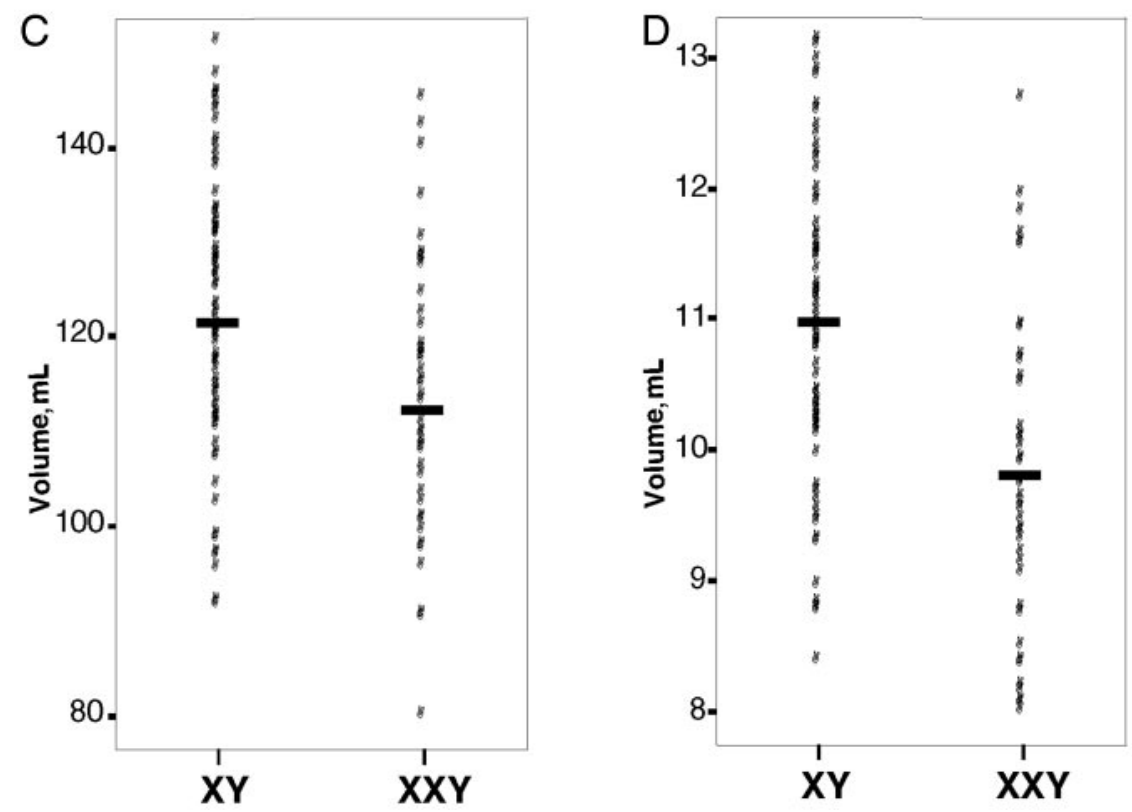

tribute to the language-learning disability of these XXY children. ${ }^{11}$

In addition to more generalized potential effects on motor function, abnormalities of the caudate nucleus have been associated with developmental speech and language dyspraxias. ${ }^{43,44}$ The reduced caudate volumes found here are consistent with the oral motor dysfunction and deficits in imitation of nonverbal mouth movements previously described in males with XXY. ${ }^{11}$ Additional investigation of this region and its influence on speech and language acquisition is warranted.

The relative sparing of gray matter and larger white matter volume in the parietal region is intriguing in light of reports indicating average or higher-level performance of XXY subjects on nonmotor perceptual tasks, which are thought to rely on intact parietal functioning. ${ }^{9,15}$ Average range ability in nonverbal visual memory, also found to rely on intact parietal functioning, ${ }^{45}$ has been found in XXY. ${ }^{8}$ In addition, XXY males seem to have a strong preference for visual stimulation, often evident within the first months of life, while showing signs of deficits in auditory localization. ${ }^{11}$ Among the Wechsler subtests, block design (particularly its spatialperception component), the subtest on which the XXY 

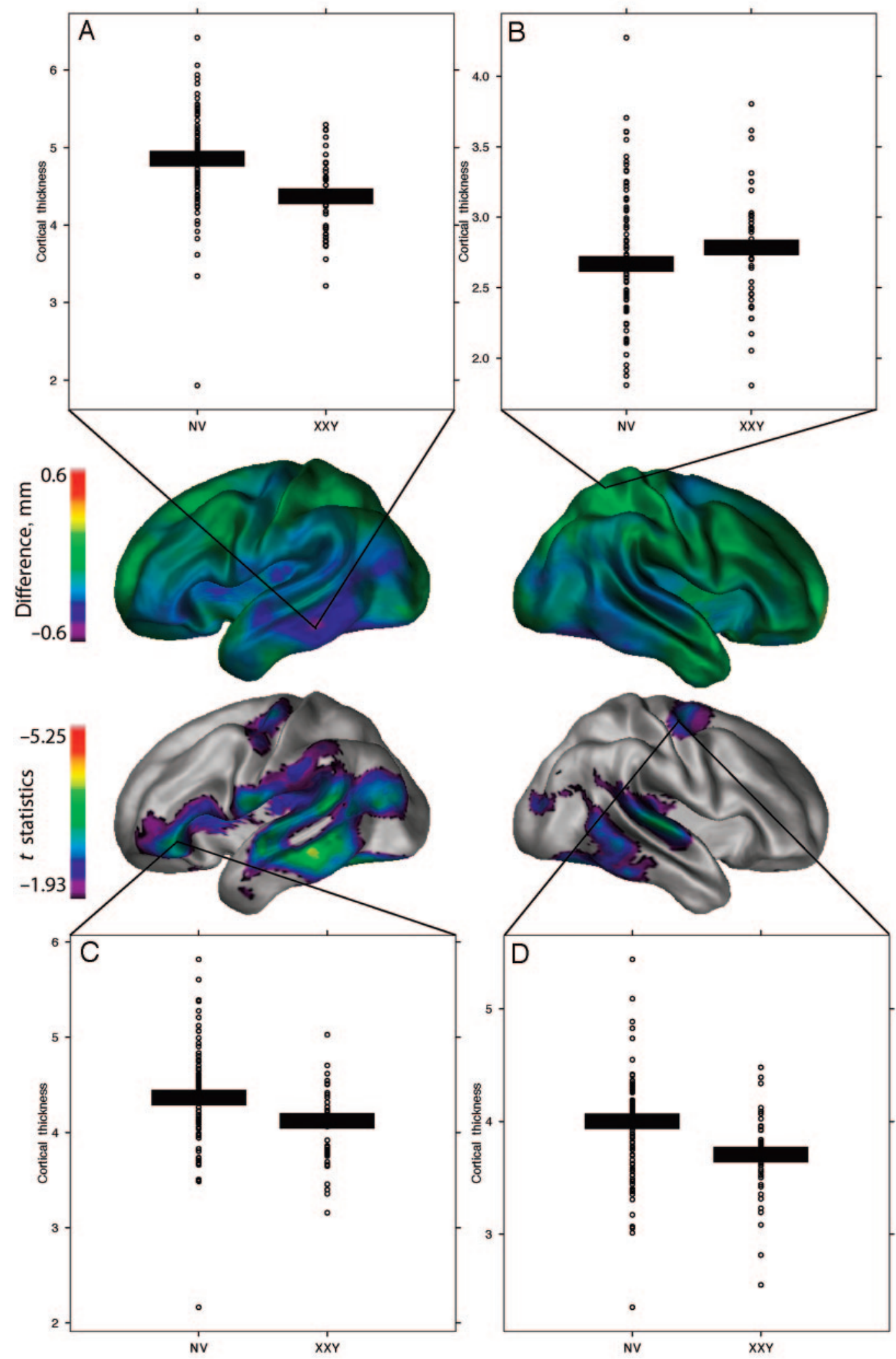

FIGURE 2

Cortical-thickness maps at each surface vertex. A and B show group mean differences in cortical thickness; C and D show the statistical significance of these differences. NV indicates normal volunteer. 
participants in our study performed best, is most strongly associated with superior parietal lobe function. ${ }^{46}$

A recent article describing the use of an automated whole-brain voxel-based morphometric technique on a subset of the data described here reported results largely consistent with these, including smaller whole-brain volumes of gray and white matter and larger ventricles in XXY subjects. ${ }^{47}$ Although direct comparison of individual structures between the 2 methods is precluded by differences in definition of anatomic areas, the automated method also found several areas with decreased gray matter in the temporal lobes, in addition to limbic and occipital regions. The 1 reported discrepancy was in parietal white matter, which was reported as smaller on the right side using the voxel-based method, in contrast to our finding that total parietal white matter was slightly larger in XXY boys. It is not clear whether this discrepancy is attributable to a true hemispheric difference or is related to differences in methods; we are currently investigating this question.

The impact of TRT on brain development in XXY males is not known. An earlier study ${ }^{2}$ of 10 adult XXY subjects and 10 controls reported that the 5 XXY subjects who had TRT showed preservation of temporal gray matter compared with those who did not receive TRT. Although this study was limited by small sample size, the known beneficial effect of TRT on physical and behavioral domains in XXY adolescents makes it plausible that TRT may have a normalizing effect on brain structural measures. We are continuing to collect data on TRT in our subjects to obtain sufficient power to determine its effects on the trajectory of brain development.

\section{CONCLUSIONS}

Brain measures in children and adolescents with XXY show regional discrepancies from control subjects consistent with their behavioral and cognitive differences. A striking characteristic of the XXY population is the wide variability of phenotypes. Many XXY individuals have no cognitive or behavioral deficits, obtain advanced degrees, and function without impairment vocationally or socially. However, study of the group differences in brain development may help clarify the mechanisms by which a supernumerary $\mathrm{X}$ chromosome affects brain development and lead to more targeted interventions.

\section{ACKNOWLEDGMENTS}

This research was supported in its entirety by the Intramural Program of the NIH, National Institute of Mental Health.

We thank the families who participated in this research and the American Association for Klinefelter Syndrome Information and Support and Klinefelter Syndrome and Associates for assisting us in the recruitment of participants.

\section{REFERENCES}

1. Linden MG, Bender BG, Robinson A. Genetic counseling for sex chromosome abnormalities. Am J Med Genet. 2002;110: 3-10

2. Patwardhan AJ, Eliez S, Bender B, Linden MG, Reiss AL. Brain morphology in Klinefelter syndrome: extra X chromosome and testosterone supplementation. Neurology. 2000;54:2218-2223

3. Nussbaum RL, McInnes RR, Willard HF, Thompson MW. Thompson $\theta$ Thompson Genetics in Medicine. 7th ed. Philadelphia, PA: Saunders; 2004

4. Thomas NS, Hassold TJ. Aberrant recombination and the origin of Klinefelter syndrome. Hum Reprod Update. 2003;9:309-317

5. Klinefelter HF, Reifenstein EC, Albright F. Syndrome characterized by gynecomastia aspermatogenesis without aleydigism and increased excretion of follicle stimulating hormone. $J$ Clin Endocrinol Metab. 1942;2:615-627

6. Varrela J, Alvesalo L. Taurodontism in 47,XXY males: an effect of the extra X chromosome on root development. J Dent Res. 1988;67:501-502

7. Bender BG, Linden MG, Robinson A. Neuropsychological impairment in 42 adolescents with sex chromosome abnormalities. Am J Med Genet. 1993;48:169-173

8. Geschwind DH, Gregg J, Boone K, et al. Klinefelter's syndrome as a model of anomalous cerebral laterality: testing gene dosage in the $\mathrm{X}$ chromosome pseudoautosomal region using a DNA microarray. Dev Genet. 1998;23:215-229

9. Geschwind DH, Boone KB, Miller BL, Swerdloff RS. Neurobehavioral phenotype of Klinefelter syndrome. Ment Retard Dev Disabil Res Rev. 2000;6:107-1 16

10. Mandoki MW, Sumner GS, Hoffman RP, Riconda DL. A review of Klinefelter's syndrome in children and adolescents [published correction appears in $J$ Am Acad Child Adolesc Psychiatry. 1991;30:516]. J Am Acad Child Adolesc Psychiatry. 1991;30: 167-172

11. Samango-Sprouse CA, Rogol A. XXY: the hidden disability and a prototype for an infantile presentation of developmental dyspraxia (IDD). Infants Young Child. 2002;15:11-18

12. Visootsak J, Aylstock M, Graham JM Jr. Klinefelter syndrome and its variants: an update and review for the primary pediatrician. Clin Pediatr (Phila). 2001;40:639-651

13. Graham JM Jr, Bashir AS, Stark RE, Silbert A, Walzer S. Oral and written language abilities of XXY boys: implications for anticipatory guidance. Pediatrics. 1988;81:795-806

14. Boone KB, Swerdloff RS, Miller BL, et al. Neuropsychological profiles of adults with Klinefelter syndrome. J Int Neuropsychol Soc. $2001 ; 7: 446-456$

15. Samango-Sprouse CA, Law P. The neurocognitive profile of the young child with XXY. Eur J Hum Genet. 2001;9(suppl 1):193

16. Temple CM, Sanfilippo PM. Executive skills in Klinefelter's syndrome. Neuropsychologia. 2003;41:1547-1559

17. Bender BG, Puck MH, Salbenblatt JA, Robinson A. Dyslexia in 47,XXY boys identified at birth. Behav Genet. 1986;16:343-354

18. Salbenblatt JA, Meyers DC, Bender BG, Linden MG, Robinson A. Gross and fine motor development in $47, \mathrm{XXY}$ and $47, \mathrm{XYY}$ males. Pediatrics. 1987;80:240-244

19. Walzer S, Graham JM Jr, Bashir AS, Silbert AR. Preliminary observations on language and learning in XXY boys. Birth Defects Orig Artic Ser. 1982;18(4):185-192

20. Mandoki MW, Sumner GS. Klinefelter syndrome: the need for early identification and treatment. Clin Pediatr (Phila). 1991;30: 161-164

21. Rovet J, Netley C, Keenan M, Bailey J, Stewart D. The psychoeducational profile of boys with Klinefelter syndrome. J Learn Disabil. 1996;29:180-196

22. Fales CL, Knowlton BJ, Holyoak KJ, Geschwind DH, Swerdloff 
RS, Gonzalo IG. Working memory and relational reasoning in Klinefelter syndrome. J Int Neuropsychol Soc. 2003;9:839-846

23. Ratcliffe SG, Masera N, Pan H, McKie M. Head circumference and IQ of children with sex chromosome abnormalities. Dev Med Child Neurol. 1994;36:533-544

24. Patwardhan AJ, Brown WE, Bender BG, Linden MG, Eliez S, Reiss AL. Reduced size of the amygdala in individuals with 47,XXY and 47,XXX karyotypes. Am J Med Genet. 2002;114: 93-98

25. Warwick MM, Doody GA, Lawrie SM, Kestelman JN, Best JJ, Johnstone EC. Volumetric magnetic resonance imaging study of the brain in subjects with sex chromosome aneuploidies. J Neurol Neurosurg Psychiatry. 1999;66:628-632

26. Wechsler D. Wechsler Abbreviated Scale of Intelligence (WASI) Manual. San Antonio, TX: Psychological Corporation; 1999

27. Wechsler D. WISC-III: Wechsler Intelligence Scale for Children: Manual. 3rd ed. San Antonio, TX: Psychological Corporation/ Harcourt Brace Jovanovich; 1991

28. Wechsler D, Corporation P. WPPSI-R, Manual: Wechsler Preschool and Primary Scale of Intelligence. Revised ed. San Antonio, TX: Psychological Corporation/Harcourt Brace Jovanovich; 1989

29. Achenbach TM, Ruffle TM. The Child Behavior Checklist and related forms for assessing behavioral/emotional problems and competencies. Pediatr Rev. 2000;21:265-271

30. Sattler JM. Assessment of Children. Revised/updated, 3rd ed. San Diego, CA: J.M. Sattler; 1992

31. Denckla MB. Revised physical and neurological examination for subtle signs. Psychopharmacol Bull. 1985;21:773-800

32. Collins DL, Neelin P, Peters TM, Evans AC. Automatic 3D intersubject registration of MR volumetric data in standardized Talairach space. J Comput Assist Tomogr. 1994;18:192-205

33. Sled JG, Zijdenbos AP, Evans AC. A nonparametric method for automatic correction of intensity nonuniformity in MRI data. IEEE Trans Med Imaging. 1998;17:87-97

34. Zijdenbos AP, Forghani R, Evans AC. Automatic "pipeline" analysis of 3-D MRI data for clinical trials: application to multiple sclerosis. IEEE Trans Med Imaging. 2002;21:1280-1291
35. Collins DL, Holmes CJ, Peters TM, Evans AC. Automatic 3-D model-based neuroanatomical segmentation. Hum Brain Mapp. 1995;3:190-208

36. MacDonald D, Kabani N, Avis D, Evans AC. Automated 3-D extraction of inner and outer surfaces of cerebral cortex from MRI. Neuroimage. 2000;12:340-356

37. Chung MK, Worsley KJ, Robbins S, et al. Deformation-based surface morphometry applied to gray matter deformation. Neuroimage. 2003;18:198-213

38. Genovese CR, Lazar NA, Nichols T. Thresholding of statistical maps in functional neuroimaging using the false discovery rate. Neuroimage. 2002;15:870-878

39. Lerch JP, Evans AC. Cortical thickness analysis examined through power analysis and a population simulation. Neuroimage. 2005;24:163-173

40. Hollingshead AdB, Redlich FC. Social Class and Mental Illness: A Community Study. New York, NY: Wiley; 1958

41. Giedd JN, Blumenthal J, Molloy E, Castellanos FX. Brain imaging of attention deficit/hyperactivity disorder. Ann N Y Acad Sci. 2001;931:33-49

42. Parent A. Cerebral cortex. In: Carpenter's Human Neuroanatomy. 9th ed. Baltimore, MD: Williams \& Wilkins; 1996:890

43. Jernigan TL, Hesselink JR, Sowell E, Tallal PA. Cerebral structure on magnetic resonance imaging in language- and learning-impaired children. Arch Neurol. 1991;48:539-545

44. Watkins KE, Gadian DG, Vargha-Khadem F. Functional and structural brain abnormalities associated with a genetic disorder of speech and language. Am J Hum Genet. 1999;65: 1215-1221

45. Todd JJ, Marois R. Capacity limit of visual short-term memory in human posterior parietal cortex. Nature. 2004;428:751-754

46. Meyer-Lindenberg A, Kohn P, Mervis CB, et al. Neural basis of genetically determined visuospatial construction deficit in Williams syndrome. Neuron. 2004;43:623-631

47. Shen D, Liu D, Liu H, Clasen L, Giedd J, Davatzikos C. Automated morphometric study of brain variation in XXY males. Neuroimage. 2004;23:648-653 
XXY (Klinefelter Syndrome): A Pediatric Quantitative Brain Magnetic Resonance Imaging Case-Control Study

Jay N. Giedd, Liv S. Clasen, Gregory L. Wallace, Rhoshel K. Lenroot, Jason P. Lerch, Elizabeth Molloy Wells, Jonathan D. Blumenthal, Jean E. Nelson, Julia W. Tossell, Catherine Stayer, Alan C. Evans and Carole A. Samango-Sprouse Pediatrics 2007;119; $232-\mathrm{e} 240$

DOI: $10.1542 /$ peds. $2005-2969$

Updated Information

\& Services

References

Subspecialty Collections

Permissions \& Licensing

Reprints including high-resolution figures, can be found at: http://www.pediatrics.org/cgi/content/full/119/1/e232

This article cites 40 articles, 10 of which you can access for free at:

http://www.pediatrics.org/cgi/content/full/119/1/e232\#BIBL

This article, along with others on similar topics, appears in the following collection(s):

Genetics \& Dysmorphology

http://www.pediatrics.org/cgi/collection/genetics_and_dysmorph ology

Information about reproducing this article in parts (figures, tables) or in its entirety can be found online at:

http://www.pediatrics.org/misc/Permissions.shtml

Information about ordering reprints can be found online:

http://www.pediatrics.org/misc/reprints.shtml 